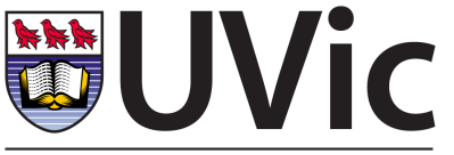

University of Victoria

Department of Economics
Econometrics Working Paper EWP1204

ISSN 1485-6441

\title{
Health and Wealth: Short Panel Granger Causality Tests for Developing Countries
}

\author{
Weichun Chen \\ Department of Economics, University of Toronto \\ Toronto, Ontario, Canada M5S $3 G 7$ \\ Judith A. Clarke \\ Nilanjana Roy \\ Department of Economics, University of Victoria \\ Victoria, B.C., Canada V8W 2 Y2
}

\begin{abstract}
The world has experienced impressive improvements in wealth and health, with, for instance, the world's real GDP per capita having increased by $180 \%$ from 1970 to 2007 accompanied by a 50\% decline in infant mortality rate. Healthier and wealthier. Are health gains arising from wealth growth? Or, has a healthier population enabled substantial growth in wealth? The answers to these questions have serious policy implications. We contribute to understanding dynamic links between wealth and health by analyzing the relationship between health (as measured by infant mortality rate) and wealth (as measured by GDP per capita) for a panel of 58 developing countries using quinquennial data covering the period 1960 through 2005. We examine for causal rather than associative links between these fundamental macro measures of economic development. The panel enables us to examine for causal links using several methods that differ in how cross-country and temporal heterogeneity is imposed: cross-country homogeneity with temporal heterogeneity and cross-country heterogeneity with temporal homogeneity. Under the latter case, we consider sensitivity to assuming fixed versus random causal coefficients. In addition, we explore robustness of outcomes to level of economic development (as measured by national income) and inclusion of another covariate (education).
\end{abstract}

Keywords: infant mortality; per capita GDP; Granger causality; fixed and random causal coefficients.

JEL Classifications: O11, I15, C33

\section{Corresponding Author Contact:}

Judith A Clarke, Department of Economics, University of Victoria, P.O. Box 1700, STN CSC, Victoria, B.C., Canada V8W 2Y2; e-mail: jaclarke@uvic.ca; Phone: (250) 721-8542; FAX: (250) 721-6214 


\section{Introduction}

Over the last century the world has experienced impressive improvements in wealth and health, with, for instance, the world's real GDP per capita having increased by $180 \%$ from 1970 to 2007 accompanied by a 50\% decline in infant mortality rate. ${ }^{1}$ Healthier and wealthier. Are health gains arising from wealth growth? Or, has a healthier population enabled substantial growth in growth in wealth? We contribute to understanding dynamic links between wealth and health across groups of countries, using panel models that allow for unobserved heterogeneity, enabling insight into the causal, rather than associative, relationship between wealth and health.

It is easy to motivate wanting to understand health-wealth links in developing economies, including providing input for policies aiming to improve well-being. Another reason is to contribute to the debate on whether development should focus on wealth growth, as higher wealth (income in particular), it is argued, leads to better health through various channels (such as nutrition, housing, sanitation, education); e.g., Caldwell (1986) and Musgrove (1996). Findings of wealth to health causality give credence to concentrating on growing income. In contrast, wealth to health noncausality suggests that income growth may not be enough, perhaps supporting advocates of "human development", focusing on the development of the state of being of people; e.g., Sen (1987) and Anand and Ravallion (1993). Feedback between health and wealth (e.g., income) suggests that the adoption of policies aiming to enhance health (such as direct income subsidies to the poor and school feeding programs) along with growth enhancing programs should have a larger impact on human development than would otherwise arise.

Many studies connect health outcomes (e.g., mortality, prevalence of disease, availability of health services, public health expenditure) with measures of socioeconomic status (e.g., income, wealth) both within and across a wide range of countries. Some of these researchers use microeconomic household or individual data; e.g., Thomas et al. (1990), Strauss and Thomas (1998), Smith (1999), Case et al. (2002), Adams et al. (2003), Contoyannis et al. (2004), Frijters et al. (2005), Michaud and van Soest (2008). Key from these microeconometric applications is that health and wealth clearly affect each other, with some demonstrating how improved health can raise education level, adult labour quantity, and labour productivity, so influencing an individual's wealth (income) via auxiliary factors. However, usually due to the nature of the datasets, most studies explore for associative, rather than causal, relationships between health and wealth; Adams et al. (2003) and Michaud and van Soest (2008) are exceptions, examining for direct causal links between health and wealth, 
analogous to the notion of Granger (1969) causality in macroeconomics - we denote this as G-causality and G-noncausality.

A large literature also uses cross-country data to study the aggregate health-wealth relationship; e.g., Rodgers (1979), Caldwell (1986), Subbarao and Raney (1995), Pritchett and Summers (1996), Filmer and Pritchett (1999), Castro-Leal et al. (2000), Devlin and Hansen (2001), Hanmer et al. (2003), Asafu-Adjaye (2004), Dreger and Reimers (2005), Erdil and Yetkiner (2009), French (2012) and Hansen (2012). Most focus on correlations, from multiple regressions that control for other relevant effects, with few considering causal links between health and wealth. Some exceptions are Devlin and Hansen (2001), Dreger and Reimers (2005) and French (2012), but their focus on OECD countries may make such works not reflect causal patterns for developing countries, as links between health and wealth likely change with level of development; see, e.g., Hanmer et al. (2003), Erdil and Yetkiner (2009) and Hansen (2012).

To our best knowledge, the dynamic causal macro papers closest in spirit to our work are Asafu-Adjaye (2004) and Erdil and Yetkiner (2009). Asafu-Adjaye (2004) estimates the causal effects of various factors on health status, measured by average life expectancy and infant mortality rate, for a panel of 44 developing and developed countries. He finds that health status is caused by real income per capita, with the magnitude of this effect differing across "low-income" and "high-income" countries. ${ }^{2}$ Absent, however, is an examination for reverse causation, an allowance for unobserved heterogeneity, and an exploration of whether causal links are heterogeneous across countries. We address each of these limitations.

Heterogeneity is allowed for in Erdil and Yetkiner's (2009) panel causality study. They use Hurlin and Venet's (2003) panel G-noncausality approach to examine links between real per capita GDP and real per capita health expenditure for 19 low-income, 32 middle-income and 24 high-income countries ${ }^{3}$ over the period 1990 through 2000. Typically, bidirectional causality is found between health expenditure and income, although there are examples of unidirectional causality, with the direction dependent on development level, as measured by real income per capita. The noted unidirectional causality tends to be from income to health expenditure for low- and middle-income countries and vice versa for high-income countries.

Given the importance of understanding the health-wealth relationship for developing countries, our purpose is to extend and examine the robustness of these aforementioned causality studies. ${ }^{4}$ We apply causality tests using quinquennial data for 58 developing countries, 1960 through $2005 .^{5}$ The methods we adopt differ in their cross-country 
heterogeneity assumptions, enabling us to examine the sensitivity of causal outcomes to such assumptions.

We explore the sensitivity of our findings in two directions. First, we ascertain robustness to income level by dividing the data into 35 middle-income countries (MICs) and 23 low-income countries (LICs). That health-wealth links likely vary with development level (as measured by income) is well noted in the literature. We also examine how causal outcomes differ when we include an ancillary variable, education, into models. We use two different education variables: average years of schooling of the total population over age 15 and for females over the age of 15.

This paper is organized as follows. In the next section we outline issues involved in measuring health and wealth, motivating our choice of metrics, real income per capita and infant mortality rate (IMR). We follow in Section 3 with a discussion on the sources of possible causal links between income and IMR, and then with descriptions of our data in Section 4 . The causality methods we adopt are subsequently detailed in Section 5, followed by our core empirical results in Section 6. Section 7 reports outcomes from our sensitivity analyses, with the final section providing our summary and concluding remarks.

\section{On measuring health and wealth}

To investigate panel causal links between health and wealth, we need appropriate metrics of these variables. Providing a summary statistic of a country's health that is comparable across countries and time is a topic with a long history; see, e.g., Sullivan (1966, 1971), Larson (1991), and Murray et al. (2000). Ideally, we desire an index of the overall health of a nation's people. Many have been proposed, but are difficult to obtain consistently across countries for an adequate time period for a causality study. Accordingly, we consider as possible metrics of a country's health status its infant mortality rate (IMR), life expectancy at birth (LEB), and child mortality rate (CMR). The IMR is the number of infants dying before reaching one year of age, per 1000 live births in a given year; the CMR is the number of children who die before reaching age five out of 1000 live births; and LEB is the number of years a newborn infant would live should prevailing patterns of mortality at the time of birth continue throughout life. ${ }^{6}$

These three metrics, as indicators of a country's health status, are deficient and have been extensively criticized. For instance, they do not directly account for the prevalence of preventable diseases or deaths, the availability of health services that improve or protect the quality of life and they provide information about only one aspect of health status, namely 
extending life or preventing premature death. Focusing on these may also result in narrow health policies that are formulated with the proxy outcome measure in mind. ${ }^{7}$ Nevertheless, nearly every country reports these statistics and they are also considered by major health organizations, such as the WHO and UNICEF. For instance, UNICEF states that "child survival lies at the heart of everything UNICEF does" " and Goal 4 of the Millennium Development Goals is to reduce infant and child mortality rates to one-third of their 1990 level by $2015 .^{9,10}$

For several reasons we adopt IMR. First, as nearly every country in the world has a goal of reducing or minimizing its IMR, causal links between health and wealth are more likely to be detected when IMR is used to measure health. Secondly, our findings can be more easily compared with other studies, given the wide spread use of IMR. Thirdly, IMR is available for a large number of years and countries. Finally, IMR indirectly accounts for factors that affect health status including education, general living conditions, quality of the environment, economic development, and availability of health services, with IMR being, in particular, responsive to improvements in pre- and postnatal care. With respect to not using CMR, we anticipate qualitatively similar results had we adopted CMR, as IMR and CMR are highly correlated. Hence, to remain consistent with most applications, we use IMR over CMR. ${ }^{11}$

We choose not to use LEB, as this statistic, usually derived from IMR data and model life tables, rather than actual death registrations, may not accurately measure patterns of mortality in developing countries (where records of death are generally incomplete). This method of construction implies there is little, if any, additional information in LEB data over IMR data. Another reason we prefer IMR over LEB is because low life expectancy in developing countries is usually a result of high infant mortality. Yet another reason for adopting IMR is that health improvements often affect this metric first, making it a useful measure in a causality study. ${ }^{12}$

Our use of IMR differs from other causality studies; e.g., Erdil and Yetkiner (2009) adopt real per capita health expenditure. Aside from wanting to employ a measure that concretely forms part of a reasonable notion of a nation's "well-being", we are also cognizant of the mixed evidence on the effectiveness of health expenditure in improving the health of the poor (e.g., Filmer and Pritchett 1999, Castro-Leal et al. 2000). Should this be the case, using health expenditure as a proxy for health status may distort causal findings between health and wealth.

Measuring a nation's "wealth" in the health-wealth literature is rarely, if at all, debated per capita income is the norm. By contrast, micro studies usually consider the individual's 
(or household's) assets and debts, along with income, as being the relevant metric; e.g., Adams et al. (2003), Contoyannis et al. (2004), Michaud and van Soest (2008). Net assets may be liquidated by the individual or household should the need arise. What about for a country? Moves towards extending the standard national income accounting notion of a country's economic performance to one of "full income" have been proposed; see, e.g., Bloom et al. (2004) and Becker et al. (2005). We are sympathetic to this growing body of work, but face the need for consistent data across countries and time. Accordingly, we take the wealth variable to be real GDP per capita, which comprises the value of final products produced over the period. As a commonly used, albeit imperfect, indicator of the level of economic development, policy is often formed based on its movements, making it a proxy for overall wealth of a country that likely influences health. We now discuss how income and infant mortality may be linked at the aggregate level.

\section{Links between income and infant mortality}

Health is a major input into the generation of a country's income according to human capital theory ${ }^{13}$, and, at the individual level, health is vital if people are to be productive. Links from health to wealth likely operate via investment, demography, education, and the labour market. Healthy people can expect to live longer, plan and save for retirement, increasing the amount of investment available to the domestic economy (e.g., Bloom et al. 2003, Zhang et al. 2003). Healthier workers can participate more productively in the labour market, and are likely to receive higher wages with benefits from this state of being (e.g., Smith 1999, Deaton 2002). Healthy workers may also impact foreign direct investment, as firms are unlikely to want to establish in countries with high mortality, illness and disease (e.g., Bloom et al. 2004).

Improvements in health may also set off a demographic transition from high to low fertility accompanying declining mortality, as parents are more confident of a child's survival, lessening a desire to have children "just in case" of death. A falling fertility rate also means that resources previously devoted to child care can be shifted to boosting family income. Health of women also improves with the lower fertility rate, which may lead to improving family circumstances. The lag between declines in mortality and fertility may result in a "baby-boom" generation, which raises economic growth when they enter the workforce (e.g., Bloom and Canning 2003). In addition, as fertility falls with lower infant and child mortality, parents are likely to invest more in their children's health and education. Healthy children are able to attend school regularly and are better able to learn with fewer nutritional deficiencies, infectious diseases and disabilities (e.g., Ruger et al. 2001, Bloom 
and Canning 2003). National income should rise in such circumstances led by the improvements in health from a lower infant mortality rate.

Classically, the relationship between health and wealth is that wealth leads to health, with health arising from the development process. Many factors likely impact infant mortality, including sanitation, parental education, clean water supply, shelter, food, available medical care and appropriate health technology, and the fertility rate; e.g., Caldwell (1986), Subbarao and Raney (1995), Pritchett and Summers (1996). As wealth (as measured by income per capita) may be regarded as a proxy for these more specific determinants of infant mortality, operating indirectly via these direct influences, we expect income to cause infant mortality.

These arguments lead to an expectation of bidirectional causality between income and infant mortality for developing countries. Health gains give rise to economic growth, which results in further health improvements and so on. This "virtuous circle" (e.g., Bloom et al. 2004) will peter off as development progresses, as infant mortality has a lower bound. Of course, a "vicious circle" (e.g., Bloom et al. 2004) is also feasible with health declines leading to income reductions followed by further deterioration in mortality. This is, perhaps, being observed in sub-Saharan Africa as a consequence of the rising HIV/AIDS infection rates.

In our bivariate models, consisting of real GDP per capita and IMR, we obtain the full causal effect of each variable on the other. Other indirect variables (such as education, availability of medical care, income inequality) are assumed to be operating through lags of income and infant mortality. To provide an indication of the sensitivity of the causal outcomes when ancillary variables are included, we also estimate trivariate systems with education as the additional variable. Unfortunately, due to data limitations, we are unable to include other possible factors. Care is needed when we compare the bivariate and trivariate outcomes as the possibility of indirect causality arises in the trivariate case, a feature not feasible in bivariate models.

We choose education as the auxiliary variable given the overwhelming evidence of the significance of this factor in reducing infant mortality, especially maternal education (e.g., Caldwell 1986, Thomas et al. 1990, Subbarao and Raney 1995, Hanmer et al. 2003). Educated parents (especially mothers), it is argued, are more likely to change traditional behaviors with respect to child rearing, seek medical attention, have better knowledge on child and maternal needs, and ensure that adequate family resources are committed to child raising. Such changes typically lead to a reduction in infant mortality. Some suggest (e.g., Thomas et al. 1990, Deaton 2002) that part of the effect of parental education on child 
survival works through income, but that there is also an independent impact. In addition, education may capture other broad socioeconomic characteristics that relate to infant mortality.

\section{Data}

Based on the World Bank's 1987 classification, there are 111 developing countries, but we are only able to use a sub-set due to data limitations: 58 developing countries for the bivariate analysis and 47 countries for the trivariate case, those having information on education. These countries form a balanced panel, each with ten quinquennial observations from 1960 through 2005. Lists of countries are provided in Table 1. Infant mortality data are from the World Bank's World Development Indicators. The quality of the IMR data has been questioned (e.g., Pritchett and Summers 1996, Farahani et al. 2009), which is one of the reasons we consider a five-year interval. Details of methods used to estimate civil registrations in developing countries are provided in, for instance, Hill et al. (2007). Ideally, mortality data are obtained from registrations covering at least 90 percent of population vital events. ${ }^{14}$ This is rare for developing countries, with information typically derived from household surveys ${ }^{15}$ or indirectly estimated from other data, including censuses. Interpolations and extrapolations are common; e.g., such techniques provide the annual figures in between the (usual) quinquennially surveys and fill in the gaps when surveys/census information is unavailable. Almost all countries lacking established civil registration have such household surveys. Hence our use of quinquennial data. ${ }^{16}$ We follow common practice of using the natural logarithm of IMR.

Table 1. Country List

Algeria, Argentina, Bolivia, Brazil, Burkina Faso, Burundi, Cameroon, Chile, Colombia,
Comoros, Congo Rep., Costa Rica, Dominican Rep., Ecuador, El Salvador, Ethiopia,
Gambia, Ghana, Greece, Guatemala, Honduras, India, Indonesia, Iran, Jamaica,
Jordan, Kenya, Lesotho, Madagascar, Malawi, Malaysia, Mali, Mauritius, Mexico,
Morocco, Nepal, Nicaragua, Niger, Nigeria, Pakistan, Panama, Paraguay, Peru,
Philippines, Portugal, Rwanda, Senegal, Sri Lanka, Syria, Tanzania, Thailand, Togo,
Trinidad and Tobago, Turkey, Uganda, Uruguay, Zambia, Zimbabwe

Notes: Using the 1987 World Bank classification, low-income countries are italicized, while the others are middle-income. Of the 58 countries, 47 are used in the trivariate models having had a complete set of quinquennial data on the education variables; these are indicated with a bold font. 
The GDP per capita data are in 2005 purchasing power parity (PPP) international dollars (I\$), taken from the Heston et al. (2011) Penn World Table 7.0; we term this real GDP per capita (GDP). ${ }^{17} \mathrm{PPP}$ is a rate of exchange for currencies that equates the purchasing power of each currency to what one dollar would acquire in the United States. We adopt standard practice of using the natural logarithm of real GDP per capita. As previous studies suggest that there is a nonlinear relationship between infant mortality and income, we believe that the double-log model adequately captures this nonlinearity over our range of infant mortality rates.

Given the evidence on the importance of education, we consider two education variables in our trivariate models: average years of schooling of the total population over age 15 (ED15) and for females over the age of 15 (EDF15). This choice reflects that schooling is often over by at most age 15 in developing countries with female education (for mothers) crucially relevant for explaining infant mortality. The education data are from Barro and Lee (2010) (see also Barro and Lee, 1993). The natural logarithm of education is employed in our models. ${ }^{18}$

Table 2 reports means for the variables (IMR, GDP, ED15 and EDF15), broken down by decade and sub-group. There have been great improvements in average IMR; e.g., the average IMR for our sample of developing countries has decreased by approximately $63 \%$ over the full period. While encouraging, a closer look reveals that improvement is uneven; IMR has gone down by about $75 \%$ for middle-income countries, whereas for low-income countries we see a decrease of about 50\%. Variation in IMR is also significantly different for the observations from 2005, being around 25-28 for middle-income countries and approximately 74-77 for low-income countries. Individual country level data also reveal diversity in IMR; e.g., IMR is 80.2 for Portugal (a middle-income country) in 1960, about the same as the average IMR for low-income countries for the 2000-2005 decade, but Portugal's IMR improved to 3.7 by 2005 . In contrast, IMR was 119.9 for the low-income country Mali in 1960 , coming down only slightly to 108.7 by 2005 , well above the average IMR for the last period for any of our sub-groups.

Looking at average GDP, we see a similar story across decades and sub-groups; overall impressive performance but large variations across sub-groups and individual countries. Average GDP by decade has increased by approximately $140-158 \%$ for all developing and middle-income countries while a relatively smaller change of around $55-70 \%$ resulted for low-income countries. While these reflect substantial improvements, variation across countries is concerning, as it is the "poorer" groups that have seen relatively slower growth. 
Table 2. Summary Statistics (Means) by Decade and Sub-Group

\begin{tabular}{|l|c|c|c|c|c|c|}
\hline \multirow{2}{*}{$\begin{array}{c}\text { Series \& Sub- } \\
\text { group }\end{array}$} & $\begin{array}{c}1960 \& \\
1965\end{array}$ & $\begin{array}{c}1970 \& \\
1975\end{array}$ & $\begin{array}{c}1980 \& \\
1985\end{array}$ & $\begin{array}{c}1990 \& \\
1995\end{array}$ & $\begin{array}{c}2000 \& \\
2005\end{array}$ & All years \\
\hline IMR - AC & 119.75 & 97.92 & 76.05 & 67.68 & 49.18 & 80.92 \\
\hline IMR - MIC & 100.21 & 79.48 & 55.37 & 39.11 & 29.59 & 60.75 \\
\hline IMR - LIC & 149.54 & 125.99 & 107.59 & 96.08 & 79.03 & 111.65 \\
\hline GDP - AC & $\$ 2,265.03$ & $\$ 3,033.76$ & $\$ 3,493.60$ & $\$ 3,787.25$ & $\$ 4,775.07$ & $\$ 3,470.94$ \\
\hline GDP - MIC & $\$ 3,247.84$ & $\$ 4,419.11$ & $\$ 5,160.94$ & $\$ 5,600.29$ & $\$ 7,138.63$ & $\$ 5,113.36$ \\
\hline GDP - LIC & $\$ 771.14$ & $\$ 926.49$ & $\$ 952.52$ & $\$ 1,020.18$ & $\$ 1,165.54$ & $\$ 967.17$ \\
\hline ED15 - AC & 2.77 & 3.60 & 4.70 & 5.77 & 6.71 & 4.71 \\
\hline ED15 - MIC & 2.96 & 3.77 & 4.91 & 6.02 & 6.97 & 5.32 \\
\hline ED15 - LIC & 2.41 & 3.18 & 4.20 & 5.26 & 6.19 & 3.29 \\
\hline EDF15 - AC & 2.32 & 3.03 & 4.10 & 5.19 & 5.92 & 4.17 \\
\hline EDF15 - MIC & 2.84 & 3.58 & 4.82 & 5.26 & 7.08 & 4.87 \\
\hline EDF15 - LIC & 1.08 & 1.74 & 2.40 & 3.26 & 4.13 & 2.52 \\
\hline
\end{tabular}

Notes: The averages are based on the countries listed in Table 1. IMR $=$ infant mortality rate; GDP = real per capita GDP; ED15 = average years of schooling for the total population over age 15; EDF15 = average years of schooling for females over age 15; $\mathrm{AC}=\mathrm{All}$ countries; $\mathrm{MIC}=$ Middle-income countries; $\mathrm{LIC}=$ Low-income countries.

Moreover, individual countries exhibit huge differences; for example, Burundi's real per capita GDP, being the lowest real GDP 2005 of the countries classified as "low-income", increased by only $42 \%$ between 1960 and 2005 . On the other hand, Portugal, which was our best performer in terms of 2005 IMR, also had a large increase in real GDP per capita with a growth of over $400 \%$ over the sample period.

The summary statistics for ED15 and EDF15 show interesting patterns; average ED15 (and EDF15) has increased by about 4 years for middle-income countries but only by about 3 years for the low-income sub-group over the sample period. The female only averages are similar to the averages for both genders for the middle-income group, but are one to two years below that for both genders for each of the periods for the low-income group. More troubling is that this gender gap has risen over the sample period. Education levels differ widely across individual countries; for 2005, Mali has the lowest ED15 of 1.54 while Niger has the lowest EDF15 of 0.93. Given these figures, it is difficult to envisage that such countries will be anywhere near achieving the United Nations Millenium Development 
Target 2.A "Ensure that, by 2015, children everywhere, boys and girls alike, will be able to complete a full course of primary schooling". ${ }^{19}$ Such low levels of education contrasts with most of the middle-income counties; for instance, Greece for 2005 has ED15=9.89 and EDF15 $=9.58$, well achieving Target 2.A. Indeed, most of the middle-income countries have achieved Target 2.A. ${ }^{20}$

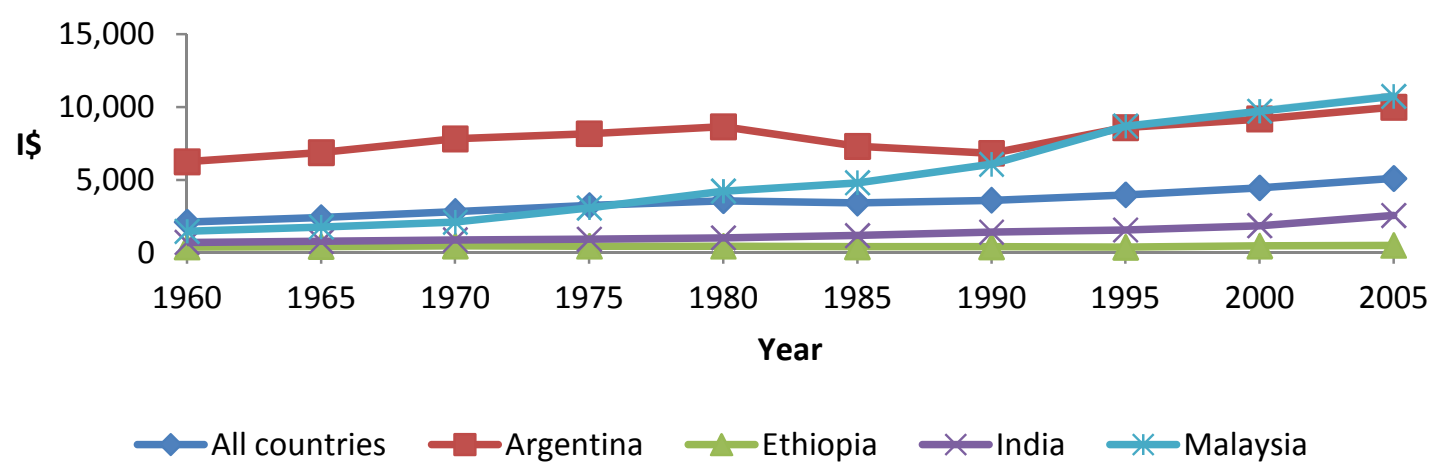

Note: "All countries" refers to average real GDP per capita for our sample of 58 countries.

Figure 1. Real GDP per capita

To illustrate, Figure 1 shows quinquennial real GDP per capita and Figure 2 presents IMRs for four representative middle- and low-income countries: Argentina, Ethiopia, India and Malaysia. Averages for our core sample of 58 countries are also plotted. The average GDP series and those for Malaysia and India are generally trending upwards with Malaysia showing the steepest trend. Ethiopia has the lowest GDP per capita among the countries

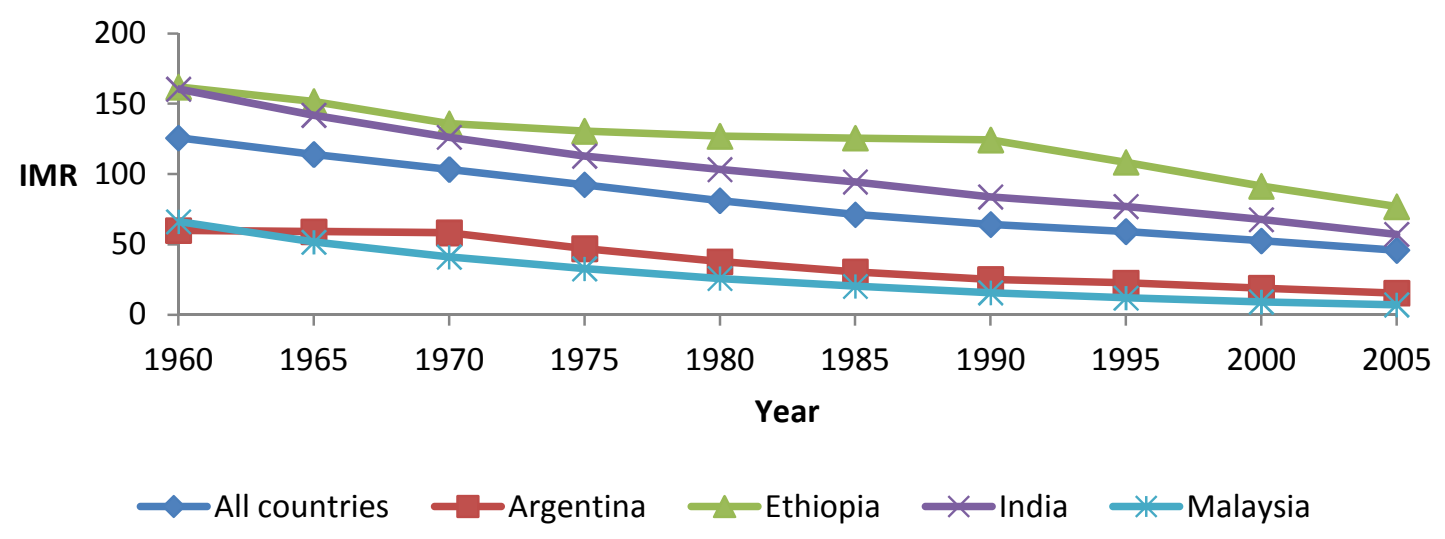

Note: "All countries" refers to average infant mortality rate for our sample of 58 countries.

Figure 2. Infant Mortality Rate 
considered in the figure, remaining relatively stagnant. Argentina, on the other hand, starts off with a much higher level of GDP but exhibits periods of poor growth over time. Average IMR is downward trending, showing, as seen by the summary statistics in Table 2, the substantial improvement in this health indicator. Although we see differences in IMR, the same general downward trend is evident.

To account for this trending (a feature for most countries), we need to ascertain whether series are better modeled as stationary around deterministic trends, as unit root processes or as strongly persistence. However, testing for unit roots in each individual series with our number of observations is not practical. An option is a panel unit root test. Such test statistics have a limiting normal null distribution as $N, T \rightarrow \infty$ with T approaching $\infty$ sufficiently fast compared with $N$, or they allow for fixed $N$, still requiring $T \rightarrow \infty$, and only a few assume fixed $T$ with $N \rightarrow \infty$. In addition, for panels with small $N$ and $T$, as with some of our groups, the tests often exhibit poor size control and low power. Accordingly, even these are not useful with our data.

Therefore, to determine information on the degree of persistence, we examined autocorrelation functions to ascertain whether there was any sign of a unit root process. Table 3 reports the range of first order sample autocorrelations. Informally, these suggest that there is persistence, but not glaring evidence of unit roots, as there are no estimates greater than 0.766 . We also report the range of first order autocorrelations after detrending, given that the autocorrelations tend to be overestimated in the presence of deterministic trends. The estimates are smaller, with the highest in magnitude being 0.645 . These results suggest that assuming trend stationarity seems reasonable.

Table 3. First Order Autocorrelation Estimates

\begin{tabular}{|l|c|c|c|c|}
\hline $\begin{array}{l}\text { Series/ } \\
\text { Statistic }\end{array}$ & $\begin{array}{c}\text { LGDP } \\
\text { [detrended] }\end{array}$ & $\begin{array}{c}\text { LIMR } \\
\text { [detrended] }\end{array}$ & $\begin{array}{c}\text { LED15 } \\
\text { [detrended] }\end{array}$ & $\begin{array}{c}\text { LEDF15 } \\
\text { [detrended] }\end{array}$ \\
\hline Mean & 0.502 & 0.678 & 0.701 & 0.706 \\
& {$[0.213]$} & {$[0.393]$} & {$[0.403]$} & {$[0.387]$} \\
\hline Minimum & -0.095 & 0.393 & 0.526 & 0.519 \\
& {$[-0.701]$} & {$[-0.346]$} & {$[-0.304]$} & {$[-0.365]$} \\
\hline \multirow{2}{*}{ Maximum } & 0.748 & 0.754 & 0.763 & 0.766 \\
& {$[0.574]$} & {$[0.645]$} & {$[0.618]$} & {$[0.607]$} \\
\hline
\end{tabular}

Notes: The "L" at the beginning of a variable name indicates that the natural logarithmic transformation has been used. 


\section{Causality methods}

We examine for causality using Granger's (1969) notion, with the premise that Gnoncausality corresponds to lack of predictability; a variable $y$ is G-noncausal for $x$ when we are unable to predict $x$ better with the past history of $y$ in the information set than when it is excluded. Assumptions with regard to heterogeneity across countries and time give many ways to examine for G-causality. Underlying is an atheoretic finite-order panel vector autoregression of order $\mathrm{p}$ :

$$
Z_{i t}=\sum_{j=1}^{p} \Gamma_{i j t} Z_{i, t-j}+\mu_{i t}+\varepsilon_{i t}, i=1, \ldots, N \& t=1, \ldots, T
$$

with $Z_{i t}$ K-dimensional. For the bivariate models $\mathrm{K}=2$ with $Z_{i t}=\left[\mathrm{LIMR}_{\mathrm{it}} \mathrm{LGDP}_{\mathrm{it}}\right]^{\prime}$ and $\mathrm{K}=3$

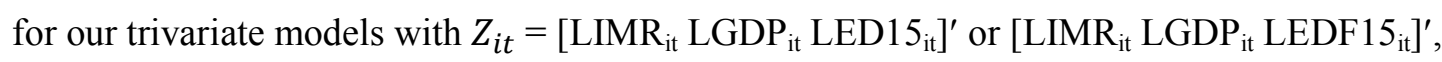
with the "L" indicating natural logarithms. The vector $\mu_{i t}$ contains country-specific and period fixed effects; $\mu_{i t}=\alpha_{i}+\beta_{t}$, accounting for both common shocks and general growth differences between countries. Although each individual series exhibits trending, we find no evidence to suggest that there is any unaccounted for trending remaining once we include the lagged covariates into the model. ${ }^{21}$ Accordingly, we allow for at most period effects. The disturbances $\varepsilon_{i t}$ are assumed to be independently distributed across countries and time, with means 0 and variances $\sigma_{i}^{2}$, permitting cross-country heteroskedasticity.

The parameter matrices, $\Gamma_{i j t}$, potentially vary with $i, j$ and $t$. As all coefficients cannot differ, we allow for temporal heterogeneity in causal links that are assumed homogenous across countries, and the converse case of country-specific causal links that are invariant over time. A specific element of $\Gamma_{i j t}$ is denoted by $\gamma_{a b, i j t}$, which are of interest in G-noncausality tests; to test for G-noncausality from LGDP to LIMR, we examine $H_{0}: \gamma_{12, i j t}=0 \forall i, j, t$ using a Wald statistic, whereas we test $H_{0}: \gamma_{21, i j t}=0 \forall i, j, t$ to determine whether LIMR is G-noncausal for LGDP. We now briefly outline our methods.

\subsection{Method I: Cross-country homogeneity, temporal heterogeneity}

This approach, proposed by Holtz-Eakin et al. (1988), assumes $\Gamma_{i j t}=\Gamma_{j t}$. Estimation is complicated by the specification of $\mu_{i t}$, as by construction the unobserved individual-level effect is correlated with the lagged dependent variables, leading to the within-estimator being inconsistent with $T$ fixed. Taking first-differences with $\Gamma_{i j t}=\Gamma_{j t}$ and re-arranging, 


$$
\begin{aligned}
Z_{i t}=\sum_{j=1}^{p+1} \prod_{j t} Z_{i, t-j}+\Delta \mu_{i t}+\Delta \varepsilon_{i t} \\
\quad i=1, \ldots, N \& t=1, \ldots, T
\end{aligned}
$$

with $\Pi_{1 t}=\Gamma_{1 t}+I_{K}, \Pi_{j t}=\Gamma_{j t}-\Gamma_{j-1, t-1}(j=2, \ldots, p), \Pi_{p+1, t}=-\Gamma_{p, t-1}$ and $\Delta \mu_{i t}=\Delta \beta_{t}$. Country effects are removed but $Z_{i, t-1}$ is correlated with the error, resolvable using, say, generalized method-of-moments (GMM) or three stage least squares (3SLS). Holtz-Eakin et al. (1988) suggest the instrument set $Q_{i t}$ formed from the elements of $Z_{i, t-2}, \ldots, Z_{i 1}$, plus a column of ones. ${ }^{22}$ We use 3SLS with these instruments, allowing for serial correlation as needed.

Elements of $\Pi_{j t}$ are $\pi_{a b, j t}$, with G-noncausality testing undertaken in two steps. We pretest for "time-stationarity", examining $H_{0}: \pi_{a b, j t}=\pi_{a b, j}, t=1, \ldots, T$ for each $a, b(a \neq$ b) using a Wald test. Time stationarity is imposed when this null is supported, with the Gnoncausality null then dependent on the outcome; it is either $H_{0}: \pi_{a b, j t}=0 \forall j, t \& a, b=$ $1,2(a \neq b)$ or $H_{0}: \pi_{a b, j}=0 \forall j \& a, b=1,2(a \neq b) .^{23}$

Although this approach allows for temporally heterogenous causal links, two drawbacks are: (i) the use of instrumental variables estimation, often shown to result in poor efficiency and significant bias (e.g., Kiviet, 1995); (ii) the assumption of common cross-country coefficients, which is likely to be violated leading to bias and inconsistency (e.g., Pesaran and Smith, 1995).

\subsection{Method II: Cross-country heterogeneity, temporal homogeneity}

Here, assuming homogenous temporal causal links, we allow for heterogenous cross-country causality. The basic framework is a restricted version of model (1), specifically

$$
Z_{i t}=\sum_{j=1}^{p} \Gamma_{i j} Z_{i, t-j}+\alpha_{i}+\beta_{t}+\varepsilon_{i t}, i=1, \ldots, N \& t=1, \ldots, T .
$$

The elements of $\Gamma_{i j}$ are denoted by $\gamma_{a b, i j}$. We examine two approaches: the first treats the causal coefficients as fixed and different whilst the second models the causal coefficients as random, arising from a distribution with constant mean and variance. For both, coefficients on lagged dependent variable regressors are treated as fixed, differing across countries; see, e.g., Hsiao (2003, p176) and Weinhold (1999).

Choosing between fixed- and random-causal coefficients is interesting; see, e.g., Pesaran et al. (1999), Hsiao (2003). First, there are estimation issues. When $N$ is large relative to $T$ 
(as here), assuming fixed-causal coefficients generally leads to lower precision than with random-causal coefficients. However, estimation bias is likely when we erroneously assume a common population. Second, is a common population a realistic assumption? Should the countries under study be close to the population, assuming fixed-causal coefficients seems preferable. However, random-causal coefficients may be more reasonable when the country group is better regarded as a sample from the population. As we use 58 developing countries from the 111 possible, it is plausible to consider random-causal coefficient models. Third, there is the question of commonality. At one extreme the causal parameters are fixed, common, and at the other extreme fixed, heterogeneous, with random-causal coefficients somewhere between. As it is difficult to know where we are on such a continuum, rather than deciding a priori, we consider the different models, examining the outcomes across them.

\subsubsection{Fixed causal coefficients}

When the causal parameters $\gamma_{12, i j} \& \gamma_{21, i j}$ are treated as fixed, different, constants, we denote least squares estimators by $\hat{\gamma}_{12, i j} \& \hat{\gamma}_{21, i j}$. Wald statistics are used to examine the Gnoncausality nulls. We consider two estimators of the variance-covariance matrix: formed from standard LS standard errors (denoted as LSSE) and from a robust to panel heteroskedasticity estimator (denoted as PCSE). Specifically, $W_{i}$ is the Wald statistic for testing $H_{0}: \gamma_{12, i j}=0 \forall j$ or $H_{0}: \gamma_{21, i j}=0 \forall j, i=1, \ldots, N$. Our short $T$ leads to concern about relying on the individual Wald tests. As shown in Hurlin (2008), the moments of $W_{i}$ differ from those of a $\chi^{2}$ variate, such that the individual tests find more causality than desired. This motivates Hurlin $(2005,2008)$ and Hurlin and Venet $(2003,2008)$ (hereafter denoted by $\mathrm{HV}$ ) to combine the Wald statistics to gain efficiency. Using HV's terminology, we examine for homogenous noncausality (HNC), which imposes G-noncausality simultaneously for all countries. The alternative hypothesis is for heterogenous noncausality (HENC), whereby Gcausality exists for at least one country. To examine the HNC null, HV average the individual Wald statistics forming $W_{N, T}=\frac{1}{N} \sum_{i=1}^{N} W_{i}$. Under sequential convergence $(T \rightarrow \infty$ followed by $N \rightarrow \infty$ ), HV show that $W_{N, T}$ converges in distribution as

$$
Z_{N, T}=\sqrt{\frac{N}{2 p}}\left(W_{N, T}-p\right) \underset{T, N \rightarrow \infty}{\stackrel{d}{\longrightarrow}} N(0,1) .
$$

Also of interest is the semi-asymptotic distribution of $W_{N, T}$ for fixed $T$ as $N \rightarrow \infty$. Then, for a balanced panel without period effects, Hurlin shows that $W_{i}$ has a finite first moment when $T>q+2$ and second moment when $T>q+4$, with $q=K p+1$ parameters $(K=$ 
2,3), leading to the result that $\ddot{Z}_{N, T}=\frac{\sqrt{N}\left[W_{N, T}-N^{-1} \sum_{i=1}^{N} E\left(W_{i}\right)\right]}{\sqrt{N^{-1} \sum_{i=1}^{N} \operatorname{Var}\left(W_{i}\right)}} \underset{N \rightarrow \infty}{\stackrel{d}{\rightarrow}} N(0,1)$. Then, for realizations of the explanatory variables, $E\left(W_{i}\right)=p(T-q) /(T-q-2) \& \operatorname{Var}\left(W_{i}\right)=$ $2 p(T-q)^{2}(T-q-2+p) /\left((T-q-2)^{2}(T-q-4)\right.$, to be used in the expression for $\ddot{z}_{N, T}$ to undertake the $H N C$ test. As $z_{N, T}>\ddot{z}_{N, T}$, use of $z_{N, T}$ leads to rejection of the $H N C$ null more than desired. However, if a sample leads to support of the $H N C$ null using $z_{N, T}$ then it would also do so with $\ddot{z}_{N, T}$. We report both $z_{N, T}$ and $\ddot{z}_{N, T}$ and their associated p-values.

Given that the least squares estimator is biased in finite samples in a lagged dependent variable model, following, for instance Bauer et al. (2012), we obtain bootstrap bias corrected estimates, using the following steps:

S1. Estimate the model by least squares and save the estimates and the residuals.

S2. Obtain a bootstrap sample using the residual bootstrap method. Use the bootstrap sample to generate new least squares estimates.

S3. Repeat step S2 to obtain B bootstrap estimates of the causal coefficients denoted by $\hat{\gamma}_{a b, i j}^{1}, \hat{\gamma}_{a b, i j}^{2}, \ldots . \hat{\gamma}_{a b, i j}^{B}$.

The bootstrap bias-corrected estimator is $\hat{\gamma}_{a b, i j}^{B C}=\hat{\gamma}_{a b, i j}-\left(\overline{\hat{\gamma}}_{a b, i j}-\hat{\gamma}_{a b, i j}\right)=2 \hat{\gamma}_{a b, i j}-$ $\overline{\hat{\gamma}}_{a b, i j}$ where $\hat{\gamma}_{a b, i j}$ is the original least squares estimator of the causal coefficient and $\overline{\hat{\gamma}}_{a b, i j}=\frac{1}{B} \sum_{l=1}^{B} \hat{\gamma}_{a b, i j}^{l}$. An estimator of the variance-covariance matrix of the bias-corrected estimator is obtained from a double bootstrap method using the following steps:

$\mathrm{SS} 1$. Undertake steps $\mathrm{S} 1$ to $\mathrm{S} 2$ to obtain the first $(\mathrm{b}=1)$ bootstrap sample and the associated least squares estimates. This becomes the parent sample. Calculate the least squares residuals from this bootstrap (parent) sample.

SS2. Repeat steps S1 and S2 using the parent sample from step SS1. Let the B1 bootstrap estimates of the causal coefficients be $\tilde{\gamma}_{a b, i j}^{1}, \tilde{\gamma}_{a b, i j}^{2}, \ldots . \tilde{\gamma}_{a b, i j}^{B 1}$. From these calculate the bootstrap bias-corrected estimate as $\tilde{\gamma}_{a b, i j}^{B C}=\tilde{\gamma}_{a b, i j}-\left(\overline{\tilde{\gamma}}_{a b, i j}-\tilde{\gamma}_{a b, i j}\right)=2 \tilde{\gamma}_{a b, i j}-\overline{\tilde{\gamma}}_{a b, i j}$ where $\tilde{\gamma}_{a b, i j}$ is the least squares estimator obtained using the parent sample and $\overline{\tilde{\gamma}}_{a b, i j}=$ $\frac{1}{B 1} \sum_{l=1}^{B 1} \tilde{\gamma}_{a b, i j}^{l}$.

SS3. Repeat steps SS1 and SS2 to obtain B bootstrap bias-corrected estimates denoted by $\tilde{\gamma}_{a b, i j}^{B C, 1}, \tilde{\gamma}_{a b, i j}^{B C, 2}, \ldots \ldots, \tilde{\gamma}_{a b, i j}^{B C, B}$. Compute the bootstrap estimator of the variance-covariance matrix as $V_{b o o t}=\frac{1}{B} \sum_{b=1}^{B}\left(\tilde{\gamma}_{a b, i j}^{B C, b}-\overline{\tilde{\gamma}}_{a b, i j}^{B C}\right)\left(\tilde{\gamma}_{a b, i j}^{B C, b}-\overline{\tilde{\gamma}}_{a b, i j}^{B C}\right)^{\prime}$ where $\overline{\tilde{\gamma}}_{a b, i j}^{B C}=\frac{1}{B} \sum_{b=1}^{B} \tilde{\gamma}_{a b, i j}^{B C, b}$.

We chose B and B1 to be 1000 . 


\subsubsection{Random causal coefficients}

Here we view the causal coefficients $\gamma_{21, i j} \& \gamma_{12, i j}$ as random draws whilst still allowing causality to vary across countries. We assume $\gamma_{a b, i j} \sim N\left(\bar{\gamma}_{a b, j}, v_{a b, j}\right) ; a, b=1,2 a \neq b$. As the other parameters are fixed and different across countries, this is dubbed a "mixed fixedand random- coefficients" (MFR) model; see, among others, Hsiao et al. (1989), Weinhold (1999), Nair-Reichert and Weinhold (2001) and Hsiao (2003, pp165-168). The variance $v_{a b, j}$ indicates the range of causal links, signaling causal heterogeneity when the estimated variance is large relative to the mean coefficient estimate. In contrast, a small variance estimate suggests that the G-causality conclusion, reached by examining $\bar{\gamma}_{a b, j}$, generally suits all countries.

We estimate $\bar{\gamma}_{a b, j}$ in two ways: generalized least squares (GLS) and mean group (MG; see, e.g., Pesaran and Smith, 1995) estimation. The MG estimator of $\bar{\gamma}_{a b, j}, \hat{\bar{\gamma}}_{a b, j}^{M G}$, given by $\hat{\bar{\gamma}}_{a b, j}^{M G}=\frac{1}{N} \sum_{i=1}^{N} \hat{\gamma}_{a b, i j}$, where $\hat{\gamma}_{a b, i j}$ is the LS estimator of $\gamma_{a b, i j}$, is consistent and asymptotically normal when $\sqrt{N} / T \rightarrow 0$ as both $N$ and $T \rightarrow \infty$ (Hsiao et al., 1999). A consistent estimator of $v_{a b, j}$ is $\hat{v}_{a b, j}^{M G}=\frac{1}{N-1} \sum_{i=1}^{N}\left(\hat{\gamma}_{a b, i j}-\hat{\bar{\gamma}}_{a b, j}^{M G}\right)^{2}$.

Alternatively, we can use GLS; see, among others, Swamy (1970), Hsiao et al. (1989), Hsiao et al. (1999), Hsiao (2003, pp 144-147). Consider the $k^{\prime}$ th equation of (3):

$$
Z_{i t}^{(k)}=\sum_{j=1}^{p} \Gamma_{i j}^{(k)} Z_{i, t-j}+\alpha_{i}^{(k)}+\beta_{t}^{(k)}+\varepsilon_{i t}^{(k)}
$$

where the superscript $(k)$ indicates the $k^{\prime}$ th row of the matrix. Our interest lies with $k=$ 1,2. To illustrate, consider the health equation in the bivariate model $(k=1$ and $K=2)$. Let: $X_{i}^{(1)}$ be the $(T \times(p+1))$ matrix whose first column is a vector of ones and the remaining $p$ columns are the observations on the dependent variable lags; $\theta_{i}^{(1)}$ be the $((p+1) \times 1)$ given by $\theta_{i}^{(1)}=\left[\alpha_{i}^{(1)} \gamma_{11, i 1} \gamma_{11, i p}\right]^{\prime} ; \gamma_{12, i}=\left[\gamma_{12, i 1} \ldots \gamma_{12, i p}\right]^{\prime} ; z_{i}^{(1)}$ be the $(T \times 1)$ vector of observations on $Z_{i t}^{(1)} ; z_{i, 1-p}^{(2)}$ be the $(T \times p)$ matrix whose columns are the lags on the causal variable wealth; $\tau$ be a $(T \times(T-1))$ matrix whose columns represent a dummy variable for each time period; $\phi^{(1)}=\left[\beta_{1}^{(1)} \beta_{2}^{(1)} \ldots \beta_{T-1}^{(1)}\right]^{\prime}$; and $\varepsilon_{i}^{(1)}$ be the $(T \times 1)$ vector of disturbances. Stacking over T, (4) is $z_{i}^{(1)}=X_{i}^{(1)} \theta_{i}^{(1)}+\tau \phi^{(1)}+z_{i, 1-p}^{(2)} \gamma_{12, i}+\varepsilon_{i}^{(1)}$. We assume: $E\left(\gamma_{12, i}\right)=\bar{\gamma}_{12}=\left[\bar{\gamma}_{12,1} \ldots \bar{\gamma}_{12, p}\right]^{\prime}, E\left(\gamma_{12, i}-\bar{\gamma}_{12}\right)\left(\gamma_{12, l}-\bar{\gamma}_{12}\right){ }^{\prime}=\Delta_{12}$ if $i=l$, 
$=0$ if $i \neq l$, and $\gamma_{12, i} \& \varepsilon_{i}^{(1)}$ are independent; the diagonal elements of $\Delta_{12}$ are the variances $v_{12, j}, j=1, \ldots, p$. Then, $\gamma_{12, i}=\bar{\gamma}_{12}+\delta_{12, i}$ with $\delta_{12, i}$ being a vector of random elements, we have $z_{i}^{(1)}=X_{i}^{(1)} \theta_{i}^{(1)}+\tau \phi^{(1)}+z_{i, 1-p}^{(2)} \bar{\gamma}_{12}+v_{i}^{(1)}$ where $v_{i}^{(1)}=z_{i, 1-p}^{(2)} \delta_{12, i}+\varepsilon_{i}^{(1)}$. It follows that $E\left(v_{i}^{(1)}\right)=0$ and, conditional on the realizations of $z_{i, 1-p}^{(2)}, \operatorname{Var}\left(v_{i}^{(1)}\right)=\sigma_{i}^{2} I_{T}+$ $z_{i, 1-p}^{(2)} \Delta_{12} z_{i, 1-p}^{(2)^{\prime}}$, with the errors uncorrelated across $i$.

Stacking over the $N$ countries, $z^{(1)}=X^{(1)} \Theta^{(1)}+\iota \otimes \tau \phi^{(1)}+z_{1-p}^{(2)} \bar{\gamma}_{12}+v^{(1)}$ with $z^{(1)}=\left[z_{1}^{(1)^{\prime}} \ldots z_{N}^{(1)^{\prime}}\right]^{\prime} ; X^{(1)}$ the $(N T \times N(p+2))$ block diagonal matrix with $X_{i}^{(1)}$ being the $i^{\prime}$ th diagonal matrix; $\Theta^{(1)}=\left[\theta_{1}^{\prime} \ldots \theta_{N}^{\prime}\right]^{\prime} ; \iota$ being a $(\mathrm{N} \times 1)$ column of ones; $z_{1-p}^{(2)}$ the $(N T \times$ $p$ ) matrix consisting of the stacked $z_{i, 1-p}^{(2)} ; v^{(1)}=D^{(2)} \delta_{12}+\varepsilon^{(1)}$, with $D^{(2)}$ being the $(N p \times N p)$ block diagonal matrix with $z_{i, 1-p}^{(2)}$ on the $i^{\prime}$ th diagonal, $\delta_{12}$ the $(N p \times 1)$ vector consisting of the stacked $\delta_{12, i}$ vectors and $\varepsilon^{(1)}$ the stacked $\varepsilon_{i}^{(1)}$ vectors. The $(N T \times N T)$ variance-covariance matrix for $v^{(1)}, \Omega^{(1)}$, is block diagonal with $i^{\prime}$ th diagonal $\sigma_{i}^{2} I_{T}+$ $z_{i, 1-p}^{(2)} \Delta_{12} z_{i, 1-p}^{(2)^{\prime}}$. Then, with $M^{(1)}=\left[X^{(1)} \iota \otimes \tau z_{1-p}^{(2)}\right]$ and $\Gamma^{(1)^{\prime}}=\left[\Theta^{(1)^{\prime}} \phi^{(1)^{\prime}} \bar{\gamma}_{12}^{\prime}\right]^{\prime}$, the GLS estimator of $\Gamma^{(1)}$ is $\Gamma_{G L S}^{(1)}=\left(M^{(1)^{\prime}}\left(\Omega^{(1)}\right)^{-1} M^{(1)}\right)^{-1} M^{(1)^{\prime}}\left(\Omega^{(1)}\right)^{-1} Z^{(1)}$ with variancecovariance matrix $V\left(\Gamma_{G L S}^{(1)}\right)=\left(M^{(1)^{\prime}}\left(\Omega^{(1)}\right)^{-1} M^{(1)}\right)^{-1}$. We use LS to estimate $\Omega^{(1)}$ to give the feasible GLS estimator, $\widehat{\Gamma}_{G L S}^{(1)}$ and its estimated variance-covariance matrix Est.V $\left(\widehat{\Gamma}_{G L S}^{(1)}\right)$; e.g., Hsiao et al. (1999). We denote this estimator of $\bar{\gamma}_{12, j}$ as $\hat{\bar{\gamma}}_{12, j}^{G L S}$. The process is then repeated to obtain the estimator of $\bar{\gamma}_{21, j}, \hat{\bar{\gamma}}_{21, j}^{G L S}$. Asymptotically, the GLS estimator is equivalent to the MG estimator (Hsiao et al., 1999). Finally, for this approach, given use of the LS estimates in forming the estimator of the mean, we use $\hat{v}_{a b, j}^{M G}$ as the estimator of $v_{a b, j}$.

Testing for G-noncausality is a test of $H_{0}: \bar{\gamma}_{a b, j}=0 ; a, b=1,2 a \neq b, \forall j$, which we test using a Wald statistic with p-values based on a limiting $\chi^{2}(p)$ null distribution. As the null relates to the mean, we also report the estimates of $v_{a b, j}$ as a measure of the degree of causal heterogeneity across countries. In addition, we generated bias-corrected versions of the GLS and $\mathrm{MG}$ estimators following similar steps to those described above for the fixed causal coefficients case. 


\section{Core empirical Granger-causality results}

Given our dearth of time periods, our core empirical findings, using 58 developing countries for the bivariate case, assume one period lag models. ${ }^{24}$ Causality results are given in Tables 4 to 6. Table 4 provides outcomes for the Holtz-Eakin et al. (1988) method that allows causal effects to vary across periods but not across countries; coefficient estimates and standard errors are reported in Appendix A, Table A.1. The first two rows of Table 4 relate to testing for time stationarity; i.e., whether the coefficients on lagged wealth and health are common over the periods. Support for time stationarity only result for the coefficients on health in the health equation. Imposing the outcomes from these time stationarity tests on the equations, the subsequent G-noncausality tests show evidence of bidirectional G-causality between health and wealth. This first method lends support to the notion that a country's current infant mortality rate depends upon per capita real income and that its per capita real GDP is also dependent on health status, as measured by IMR.

Table 4. Method I - Time stationarity and G-noncausality tests for 58 developing countries

\begin{tabular}{|l|c|c|}
\hline Test & Health Equation & Wealth Equation \\
\hline TS: Wealth (p-value) & $19.475(0.078)$ & $30.742(0.002)$ \\
\hline TS: Health (p-value) & $15.418(0.220)$ & $35.236(0.000)$ \\
\hline G-noncausality (p-value) & $45.830(0.000)^{*}$ & $42.948(0.000)^{* *}$ \\
\hline
\end{tabular}

Notes: Figures are the Wald statistics (associated $\chi^{2} \mathrm{p}$-value in parentheses) for time stationarity (TS) and G-noncausality tests. ${ }^{*}$ The null is for testing whether wealth is Gnoncausal for health (associated $\chi^{2} \mathrm{p}$-value in parentheses); ${ }^{* *}$ The null corresponds to whether health is G-noncausal for wealth (associated $\chi^{2} \mathrm{p}$-value in parentheses).

Turning to the core results for the 58 countries from testing the $H N C$ null from the approach of HV that allows for heterogeneity in country causal patterns, Table 5 presents causality outcomes; given the number of estimates, we do not report them all (they are available on request). Instead, Table A. 2 of Appendix A presents summary details on the range of estimates across countries and for four representative countries: Argentina, Ethiopia, India and Malaysia; these highlight the wide range of estimates observed. Concentrating on the LS estimates of the causal parameters of interest, our prior economic expectation is for negative estimates; improvements in real GDP per capita should lead to reductions in infant mortality rate and vice versa. We see this for 48 (of the 58) countries when considering the wealth equation. Of the 10 cases where the estimates of the causal parameter are positive, only three are statistically significant at common levels of significance. For the health equation, we find that wealth negatively causally impacts infant mortality for 22 countries and, while there are 36 positive estimates of the causal effect, only two of these are 
statistically significant. These findings strongly highlight the heterogeneity in estimates across countries, stressing one of the difficulties of working with heterogeneous panels. The causal parameter estimates for the four representative countries further illustrate the heterogeneity and insignificance issues.

Irrespective of estimator or method used to provide standard errors, we observe bidirectional causality between our wealth and health variables, supporting our findings from Method I (see Table 4), when using the $z_{N, T}$ statistics. This outcome is not sensitive to the use of the finite sample correction factor suggested by Hurlin $(2005,2008)$, except when using the LSSEs when testing whether wealth is causal for health. Overall, these findings suggest that it does not matter whether we impose cross-country homogeneity or temporal homogeneity in causal links.

Table 5. Method II with fixed causal coefficients - G-noncausality tests for 58 developing countries

\begin{tabular}{|l|c|c|c|}
\hline & $W_{N, T}$ & $Z_{N, T}$ (p-value) & $\ddot{Z}_{N, T}$ (p-value) \\
\hline \multicolumn{4}{|c|}{ Health Equation } \\
\hline LS with LSSEs & 1.533 & $2.870(0.004)$ & $0.075(0.940)$ \\
\hline LS with PCSEs & 2.651 & $8.890(0.000)$ & $2.613(0.009)$ \\
\hline Bias-corrected estimates & 9.913 & $47.998(0.000)$ & $19.102(0.000)$ \\
\hline \multicolumn{4}{|c|}{ Wealth Equation ${ }^{* *}$} \\
\hline LS with LSSEs & 2.372 & $7.388(0.000)$ & $1.980(0.048)$ \\
\hline LS with PCSEs & 3.232 & $12.020(0.000)$ & $3.933(0.000)$ \\
\hline Bias-corrected estimates & 3.237 & $12.046(0.000)$ & $3.944(0.000)$ \\
\hline
\end{tabular}

Notes: The statistic $W_{N, T}$ is the average of the individual country Wald statistics for testing G-noncausality. The standard normal z-statistics are used to examine the G-noncausality null hypothesis, with $\ddot{z}_{N, T}$ adjusted for finite-sample moments. ${ }^{*}$ The null is for testing whether wealth is G-noncausal for health. ${ }^{* *}$ The null corresponds to whether health is G-noncausal for wealth.

The causality results presented in Table 5 do not account for the empirical feature that for 13 of the 58 countries $^{25}$ the least squares estimates imply explosive roots, contrary to expectations that roots of the vector autoregression are at most unity. ${ }^{26}$ For ten of these cases, the explosive root is in IMR, whereas it is in GDP for the remaining three (India, Indonesia and Paraguay). This may be from the bias associated with least squares in small samples (e.g., Andrews and Chen 1994, Qureshi 2008); e.g., Qureshi's (2008) simulations show that least squares can have a high frequency of estimated explosive roots even when the variables are indeed stationary.

That we observe estimated roots greater than one in magnitude may also be implying data exhibiting exponential growth, past shocks have an increasingly large effect on the present so 
that the variance increases exponentially in $t$; e.g., see Sims (1989) for discussion and Juselius and Mladenovic (2002) for an illustration. An examination of the data for these 13 series shows (typically) increasingly higher growth rates (in magnitude), consistent with an explosive root for six cases (Brazil, El Salvador, India, Malaysia, Peru and Turkey). For another five series (Congo Republic, Indonesia, Madagascar, Niger and Philippines), there are possible structural breaks that are perhaps leading to the observed explosive root. There seems to be a combination of increasing growth rates and a structural break for the series of issue for the Dominican Republic and Paraguay. To ensure that the cases with structural breaks were not distorting outcomes, we repeated the analysis deleting them from the dataset. Similar qualitative outcomes (available on request) resulted, leading us to continue including these cases.

Table 6 contains causality results assuming random causal coefficients using the MG and GLS estimators. The qualitative causality outcomes are the same for both estimators, and whether we bias correct or not, with evidence of causality from health to wealth (at least at the nominal $15 \%$ significance level) but no support for wealth to health causality. The variance

Table 6. Method II with random causal coefficients - G-noncausality tests for 58 developing countries

\begin{tabular}{|c|c|c|c|c|}
\hline & MG & $\begin{array}{c}\text { Bias corrected } \\
\text { MG }\end{array}$ & GLS & $\begin{array}{c}\text { Bias corrected } \\
\text { GLS }\end{array}$ \\
\hline \multicolumn{4}{|c|}{ Health Equation $^{*}$} \\
\hline$\hat{\bar{\gamma}}_{12,1}$ & -0.054 & -0.038 & -0.049 & -0.040 \\
$($ se) & $(0.044)$ & $(0.044)$ & $(0.048)$ & $(0.034)$ \\
\hline $\begin{array}{c}\text { Wald statistic } \\
\text { (p-value) }\end{array}$ & 1.454 & 0.748 & 1.047 & 1.355 \\
\hline$\hat{v}_{12,1}$ & $0.228)$ & $(0.387)$ & $(0.306)$ & $0.244)$ \\
\hline \multicolumn{4}{|c|}{ Wealth Equation ${ }^{* *}$} \\
\hline$\hat{\bar{\gamma}}_{21,1}$ & -0.237 & -0.154 & 0.115 & 0.112 \\
(se) & $(0.057)$ & $(0.053)$ & -0.149 & -0.115 \\
\hline Wald statistic & 17.130 & 8.570 & 4.150 & $(0.078)$ \\
(p-value) & $(0.000)$ & $(0.003)$ & $(0.042)$ & 2.180 \\
\hline$\hat{v}_{21,1}$ & 0.186 & 0.161 & 0.186 & $0.140)$ \\
\hline
\end{tabular}

Notes: ${ }^{*}$ The null is for testing whether wealth is G-noncausal for health. ${ }^{* *}$ The null corresponds to whether health is G-noncausal for wealth.

estimate $\hat{v}_{12,1}$ is more than twice that of the estimated mean coefficient, whereas $\hat{v}_{21,1}$ is similar to the magnitude of the estimated mean coefficient. This suggests that the finding that wealth is noncausal for health, based on the mean, may not be the case for all countries, as 
there is signs of causal heterogeneity. In contrast, the causality finding of health to wealth, based on the mean estimate, may well be reasonable for all countries.

Our results indicate that the causality outcome between wealth and health is sensitive to the assumption made regarding the causal coefficient. When we assume fixed coefficients we detect bidirectional causality, consistent with the notion of a "virtuous circle". However, assuming random causal coefficients, drawn from a normal distribution with a common mean, there is evidence of causality from health to wealth but the notion of "wealthier is healthier" is no longer supported. However, we suspect causal heterogeneity in this latter case such that the mean estimate is not representative of the causal link from wealth to health for all countries. This leads us to prefer the assumption of cross-sectional heterogeneity with fixed causal coefficients, concluding that our countries are likely not a sample from a common population.

In summary, given our preference for the fixed coefficients assumption, our results advocate improving health, specifically reducing infant mortality in developing countries, to lead to a positive impact on level of economic development, as measured by real GDP per capita. In addition, we find evidence that increases in GDP per capita can lead to a reduction in infant mortality; a virtuous circle between health and wealth. Our findings are consistent with those reported in Asafu-Adjaye's (2004) study of 44 developing and developed countries and to the overall results of Erdil and Yetkiner (2009), in their exploration of causality between real per capita GDP and real per capita health expenditure. Next, we briefly explore the sensitivity of our causality results to disaggregating the countries and to changing the information set.

\section{Sensitivity analyses}

\subsection{Decomposition by income group}

Using the World Bank's classification based on GDP per capita in constant 1987 US\$, we sorted the 58 countries into 23 low- and 35 middle-income countries. The variation in income across these groups is substantial - from less than 481US\$ to 6,000 US\$ per capita. ${ }^{27}$ To examine the sensitivity of our causality results to this disaggregation, we provide, in Table 7, causal outcomes for low- and middle-income countries under the fixed coefficients assumption that allows for cross-country heterogeneity while assuming temporal homogeneity. ${ }^{28}$

Predominantly the causality results for middle-income countries mirror those found for the full sample of countries, at least at the nominal $15 \%$ significance level. Such is not the 
case, however, for the low-income countries, where outcomes differ more across estimators and from those observed for all countries, particularly when examining for wealth to health causality. Specifically, the results seem to support health to wealth causality with limited evidence of wealth to health causality. That the sub-Saharan African countries, suffering from HIV/AIDS concerns, fall within the low-income group is likely contributing to the finding of noncausality from wealth to health. Many of the low-income countries have also suffered from long term political issues, conflicts, famines and other crises that are also likely contributing to this outcome. Our analysis in this subsection highlights that health and income policies may need to depend on level of development, as measured by income per capita.

Table 7. Method II with fixed causal coefficients - G-noncausality tests for low- and middleincome countries

\begin{tabular}{|l|c|c|c|c|c|c|}
\hline & \multicolumn{2}{|c|}{$W_{N, T}$} & \multicolumn{2}{c|}{$z_{N, T}$ (p-value) } & \multicolumn{2}{c|}{$\ddot{z}_{N, T}$ (p-value) } \\
\hline \multicolumn{7}{|c|}{ Health Equation } \\
\hline Estimator/Country Group & MIC & LIC & MIC & LIC & MIC & LIC \\
\hline LS with LSSEs & 2.341 & 1.929 & $\begin{array}{c}5.612 \\
(0.000)\end{array}$ & $\begin{array}{c}3.151 \\
(0.002)\end{array}$ & $\begin{array}{c}1.484 \\
(0.138)\end{array}$ & $\begin{array}{c}0.613 \\
(0.540)\end{array}$ \\
\hline LS with PCSEs & 2.333 & 3.110 & $\begin{array}{c}5.576 \\
(0.000)\end{array}$ & $\begin{array}{c}7.156 \\
(0.000)\end{array}$ & $\begin{array}{c}1.469 \\
(0.142)\end{array}$ & $\begin{array}{c}2.302 \\
(0.021)\end{array}$ \\
\hline Bias-corrected estimates & 2.920 & 1.599 & $\begin{array}{c}8.033 \\
(0.000)\end{array}$ & $\begin{array}{c}2.031 \\
(0.042)\end{array}$ & $\begin{array}{c}2.505 \\
(0.012)\end{array}$ & $\begin{array}{c}0.141 \\
(0.888)\end{array}$ \\
\hline \multicolumn{7}{|c|}{ Wealth Equation } \\
\hline Estimator/Country Group & MIC & LIC & MIC & LIC & MIC & LIC \\
\hline LS with LSSEs & 1.780 & 1.068 & $\begin{array}{c}3.262 \\
(0.001)\end{array}$ & $\begin{array}{c}0.230 \\
(0.818)\end{array}$ & $\begin{array}{c}0.493 \\
(0.622)\end{array}$ & $\begin{array}{c}-0.618 \\
(0.537)\end{array}$ \\
\hline LS with PCSEs & 2.445 & 2.835 & $\begin{array}{c}6.045 \\
(0.000)\end{array}$ & $\begin{array}{c}6.224 \\
(0.000)\end{array}$ & $\begin{array}{c}1.667 \\
(0.096)\end{array}$ & $\begin{array}{c}1.909 \\
(0.056)\end{array}$ \\
\hline Bias-corrected estimates & 3.859 & 11.438 & $\begin{array}{c}11.960 \\
(0.000)\end{array}$ & $\begin{array}{c}35.396 \\
(0.000)\end{array}$ & $\begin{array}{c}4.161 \\
(0.000)\end{array}$ & $\begin{array}{c}14.209 \\
(0.000)\end{array}$ \\
\hline
\end{tabular}

Notes: MIC $=$ Middle-income countries; LIC $=$ Low-income countries. The statistic $W_{N, T}$ is the average of the individual country Wald statistics for testing G-noncausality. The standard normal z-statistics are used to examine the G-noncausality null hypothesis, with $\ddot{z}_{N, T}$ adjusted for finite-sample moments. ${ }^{*}$ The null is for testing whether wealth is G-noncausal for health. ${ }^{* *}$ The null corresponds to whether health is G-noncausal for wealth.

Our finding of unidirectional causality from health to wealth (except when using LSSEs) for low-income countries differ somewhat from those of Erdil and Yetkiner (2009), who report that there is predominantly bidirectional causality between health care expenditure and income for LICs with only a few countries exhibiting no causality from health to wealth. Our different results may be a facet of some variation in the sample of countries defined as low- 
income, but we also suspect that it may well be arising from our different ways of measuring health. An outcome of causality from national income to health care expenditure does not necessarily translate into a causal link from national income to infant mortality, as it is well recognized that it is usually the most vulnerable who have the least access to health care services; e.g., Filmer and Pritchett (1999) and Hanmer et al. (2003).

In contrast, for middle-income countries our evidence of bidirectional causality is consistent with the dominant outcomes reported by Erdil and Yetkiner (2009) for their sample of middle-income countries. Perhaps once a certain level of development is achieved, as measured by real GDP per capita, increases in health care expenditure and declines in infant mortality do tend to occur alongside each other.

In summary, our interpretation is that the feedback between health and wealth observed for middle-income countries suggest policies that sustain both wealth and health. However, for low-income countries, focusing limited resources on reducing infant mortality appears to be a good strategy. Once these countries reach a level of income that allows for a virtuous cycle between health and wealth, policies should aim to improve both wealth and health simultaneously.

\subsection{Inclusion of education in the information set}

In this subsection, we briefly examine the sensitivity of our findings to the inclusion of another covariate, education, into the information set. We base this choice of ancillary variable on the well-established links between education and health, and education and wealth in the literature; e.g., Subbarao and Raney (1995) and Gregorio and Lee (2003). We consider two education variables: ED15 (average years of schooling for the population over 15 years of age) and EDF15 (average years of schooling for females over 15 years of age). The first education metric is often used to measure aggregate education level in a population (e.g., Gregorio and Lee 2003, Hazan 2012). We examine the second education measure, which considers only females, as there is strong evidence in the literature about the importance of the education of females on children's health (e.g., Subbarao and Raney 1995, Zakir and Wunnava 1999). For space reasons, we report causality outcomes in the form of Granger-causal maps, where the direction of an arrow indicates a causal link, using a nominal $15 \%$ significance level. The maps, reported in Table 8, are based on the fixed causal coefficients model allowing for cross-country heterogeneity (Method II) using LS with PCSEs; maps for other estimators are available on request. Given the apparent importance of 
Table 8. Granger-causal maps when education is included in the information set

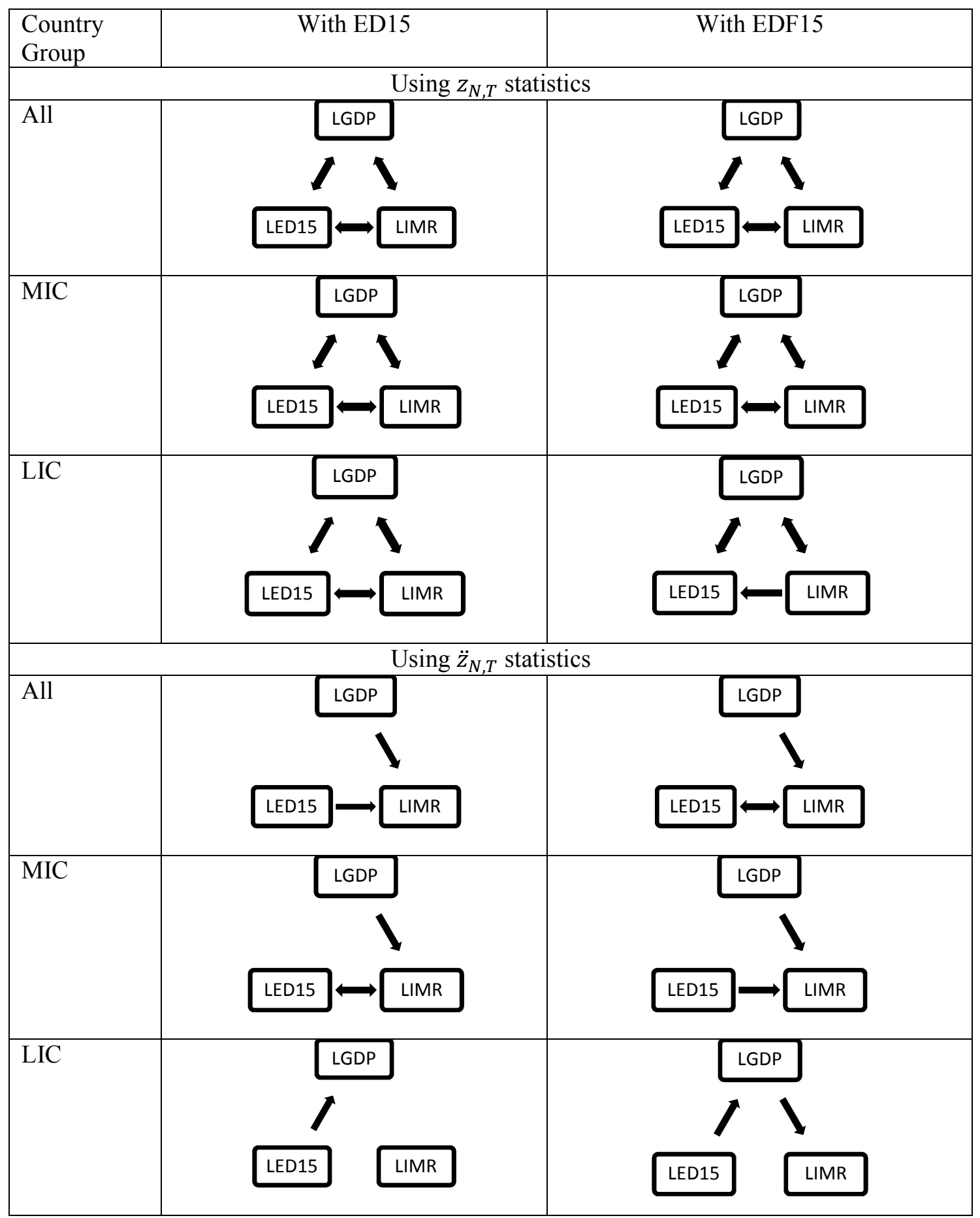

Notes: The direction of an arrow indicates a causal link, at the nominal 15\% significance level; All = All (47) countries; MIC = Middle-income (33) countries; LIC = Low-income (14) countries. Outcomes are based on LS with PCSEs from the fixed causal coefficient models with cross-country heterogeneity (Method II). 
level of development, we report causal maps for all countries and disaggregated into low- and middle-income groups.

When using the $z_{N, T}$ statistics, we observe mostly bidirectional causality between the variables, irrespective of whether we disaggregate by income group and which education variable is included in the information set. These outcomes suggest the importance of education in aiding improvements in wealth and health. However, when using the $\ddot{Z}_{N, T}$ statistics, far fewer causal outcomes are detected, with education often not linked with health or wealth, and health is noncausal for wealth across all groupings. In contrast, wealth is causal for health. Although it is known that the use of $z_{N, T}$ statistics can over-reject a valid noncausal null hypothesis, we find the paucity of causal links using the $\ddot{z}_{N, T}$ statistics surprising, given the often cited research that highlights the importance of education.

However, this feature may well be resulting from the different interpretations of Grangercausality between a bivariate system and one that contains auxiliary variables, not under test when ascertaining causal links. Specifically, as well discussed by Dufour and Renault (1998) (see also Dufour et al. 2006), Granger's concept of causality relates to predictability oneperiod ahead so that noncausality in a trivariate system between two variables does not imply noncausality at higher horizons, as indirect causality may arise via the auxiliary variable at a higher horizon. In a bivariate system, as there are no auxiliary variables, noncausality at horizon-one implies noncausality at all horizons. For instance, for LICs when using $\ddot{z}_{N, T}$, we detect horizon-one causality from EDF15 to GDP and from GDP to IMR, but no causality between health and education, contrary to expectations. This causal map, however, suggests the feasibility of causality from EDF15 to IMR via GDP at a higher horizon. Such possible higher horizon causal links may explain the apparent paucity of horizon-one causal links evident in Table 10 when using the $\ddot{z}_{N, T}$ statistics. Unfortunately, due to data limitations, we are unable to apply the approach of Dufour et al. (2006) to examine for such indirect causality patterns, leaving such an analysis for future work when more data is available.

In summary, our small sensitivity analysis suggests that education matters in understanding the links between health and wealth, as does also the level of development. This work also highlights the issues that must be considered when introducing auxiliary variables into the information set when exploring causal links.

\section{Summary and concluding remarks}

Knowledge of links between wealth and health is important information for developing countries pursuing economic and human development. We contribute to the body of work 
that explores for such links, examining whether there is evidence of causality between a commonly adopted metric of a country's wealth, real GDP per capita, and a concrete metric of health status, the infant mortality rate. We deliberately adopted this measure for health rather than another popular measure, real health care expenditure per capita, given our belief that development is about well-being with a need to focus on direct measures of health status.

To determine causal links, we adopted panel causality methods that vary in their assumptions regarding cross-country heterogeneity, temporal heterogeneity and whether the causal coefficients are assumed to arise from some common distribution. We considered a variety of estimators and approaches to obtaining standard errors, including bias correcting due to the presence of a lagged dependent variable regressor in our models. In addition, we explored the sensitivity of our findings to level of economic development (as measured by real GDP per capita) and to expanding the bivariate models to trivariate ones that contain an ancillary variable, education, given the evidence of the importance of education on improving health and wealth; we considered two education variables to examine sensitivity. This extension to trivariate models also enabled us to highlight the issues that can arise in understanding causal links at different horizons.

With the bivariate models, consisting only of health and wealth, our results are reasonably robust for the full sample of countries. Our overarching finding is for bidirectional causality between real GDP per capita, our metric for wealth, and the infant mortality rate, our metric for health. This finding supports the work that adopts health care expenditure as the measure of health, and many cross-sectional multivariate studies that explore such questions; income matters in helping infants survive and survival of infants, via a variety of channels, results in higher income. Policies that support growth in income and directly address reducing infant mortality are desirable strategies for development.

Splitting countries by income level into low-income and middle-income countries, we find that the causality results for middle-income countries are generally consistent with those for the full sample of countries. For low-income countries, the outcomes are not as clear cut, with some signs of noncausality between wealth and health. As the sub-Saharan African countries form part of this group, we suspect that this outcome is associated with the HIV/AIDS crisis that has severely affected these countries. It is likely also a facet of the conflicts, political difficulties, famines and other crises that have severely impacted many of these countries. Although we are unable to specifically identify factors, it is clear that the causal links between wealth and health do differ across level of economic development, as measured by real GDP per capita. 
Including education into the models affected causal links, especially when we use statistics better suited to the panel under study. Using these statistics, we detect no evidence of causality from health to wealth, irrespective of income level. We stress, however, that these causal linkages are only at horizon one, and need not reflect indirect causal links that may arise from health to wealth via education at higher horizons. One needs to be cautious in comparing causality results from models with auxiliary variables to those from bivariate models. Due to insufficient temporal observations, it was not feasible to explore for these indirect causal links.

There are several directions of research that we believe should be considered in future work. Key to these is the availability of quality data of adequate time spans. Topics include: exploring alternative and, more representative, measures of wealth and health; ascertaining the stability of causal links over time; testing for indirect causality arising between wealth and health from other factors; and determining the robustness of findings to other ways to model dynamic panels.

\section{Acknowledgments}

We thank Merwan Engineer and Thanasis Stengos for comments and suggestions on an earlier draft of this paper, Diana Weinhold for helpful correspondence, and participants at meetings of the Western Economic Association and the Canadian Economic Association for useful feedback.

\section{Notes}

1.World Bank's online World Development Indicators with GDP per capita measured in constant 2005 \$US and the infant mortality rate expressed as infant deaths per 1000 live births.

2. A cut-off income of US $\$ 5,000$ per capita is adopted in this work.

3. Based on the World Bank's classifications.

4.Preliminary work for this paper was undertaken for the fourth chapter of the first author's $\mathrm{PhD}$ dissertation, published as Chen (2010). This work differs in a number ways. First, we have included a detailed literature review and data summary. Second, we extended the data to include 2005. Third, given the long period of time considered (1960 to 2005), we control for period effects. Fourth, we use a number of different estimators not considered in Chen (2010) including the mean group estimator and bootstrapped bias corrected estimators. Finally, we have included another education variable in our sensitivity analysis 
that is more standard in the current literature (ED15, average years of schooling for the total population over age 15$)$.

5. We define a developing country as one that falls into the World Bank's categories of lowincome and middle-income. Also, as a number of countries (e.g., Greece, Malta, Portugal, and Trinidad and Tobago) moved, over the last two decades, from being classified as middle-income to high-income, we adopted the World Bank's 1987 groupings, the year that the Bank began classifying in this way and a point roughly half way through our sample of years.

6.Life expectancy is calculated by applying age and sex-specific mortality rates from the population under study to a hypothetical birth cohort of 100,000 individuals.

7.See, e.g., Murray et al. (2000).

8. See http://www.unicef.org/mdg/childmortality.html, last accessed 29 August 2012.

9. See http://www.who.int/mdg/goals/goal4/en/, last accessed 29 August 2012.

10.Eight Millennium Development Goals, adopted by member countries of the United Nations, arose from the 2000 Millennium Summit. A complete list of the goals is available at http://www.undp.org/mdg, last accessed 29 August 2012.

11.Several empirical studies report close qualitative agreement for income effects on CMR and IMR; e.g., Easterly (1999), Filmer and Pritchett (1999) and Hanmer et al. (2003).

12.See, e.g., Bloom et al. (2004).

13.See, e.g., Mushkin (1962).

14.See, for instance, World Development Indicators, Volume 2006, p123.

15.World Fertility Surveys in the early part of the sample and Demographic and Health Surveys (Macro International) and Multiple Cluster Surveys (UNICEF) for the later observations.

16.Other related empirical works adopt a quinquennial interval for similar reasons; e.g., Pritchett and Summers (1996) and Farahani et al. (2009).

17.Specifically, we use RGDPCH; see http://pwt.econ.upenn.edu/php_site/pwt70/pwt70_form.php, last accessed 29 August 2012. 18.See http://www.barrolee.com/; last accessed 29 August 2012.

19.See http://www.un.org/millenniumgoals/education.shtml, last accessed 29 August 2012.

20. Out of 33 middle-income countries, only Cameroon, Guatemala, Senegal and Syria have not achieved average schooling years of more than six years.

21.Details of this preliminary investigation are available on request. 
22. A necessary condition for identification is that there are at least as many instruments as right-hand side variables. As there are $[\mathrm{K}(\mathrm{p}+1)+1]$ variables on the right-hand side of equation (2) and the number of distinct elements in $Q_{i t}$ is $[\mathrm{K}(\mathrm{t}-2)+1]$, we require $\mathrm{t} \geq(\mathrm{p}+3)$.

23. We recognize the pre-testing complications introduced by such a testing strategy.

Exploration of this is left for future work.

24.It would be interesting to explore the sensitivity of our findings to the lag order assumption when additional quinquennial data are available.

25.These countries are Bolivia, Brazil, Comoros, Ecuador, El Salvador, Guatemala, India, Indonesia, Morocco, Nepal, Niger, Pakistan, Peru, Philippines, Tanzania, Thailand, Turkey and Uruguay.

26.For the $\operatorname{VAR}(1)$ to be stationary, we require that the roots of $\left|\Gamma_{i 1}-\lambda I\right|=0$ lie inside the unit circle.

27.See http://data.worldbank.org/about/country-classifications/a-short-history and the excel file therein, last accessed 29 August 2012.

28.We also generated causal links under the random coefficients assumption, which are available on request.

\section{References}

Adams, P., M.D. Hurd, D. McFadden, A. Merrill, and T. Ribeiro. 2003. Healthy, wealthy, and wise? Tests for direct causal paths between health and socioeconomic status. Journal of Econometrics 112: 3-56.

Anand, S., and M. Ravallion. 1993. Human development in poor countries: On the role of private incomes and public service. Journal of Economic Perspectives 7: 133-50.

Andrews, D.W.K., and H. Chen. 1994. Approximately median-unbiased estimation of autoregressive models. Journal of Business \& Economic Statistics 12: 187-204.

Asafu-Adjaye, J. 2004. Income inequality and health: A multi-country analysis. International Journal of Social Economics 31: 195-207.

Barro, R.J., and J.-W. Lee. 1993. International comparisons on educational attainment. Journal of Monetary Economics 32: 363-94.

Barro, R.J., and J.-W. Lee. 2010. A new data set of educational attainment in the world, 1950-2010, NBER Working Paper No 15902.

Bauer, M.D., G.D. Rudebusch, and J.C. Wu. 2012. Correcting estimation bias in dynamic term structure models. Journal of Business and Economic Statistics, forthcoming.

Becker, G.S., T.J. Philipson, and R.R. Soares. 2005. The quantity and quality of life and the evolution of world inequality. The American Economic Review 95: 277-91.

Bloom, D.E., and D. Canning. 2003. The health and poverty of nations: From theory to practice. Journal of Human Development 4: 47-71.

Bloom, D.E., and D. Canning. 2004. The health and wealth of Africa. World Economics 5: 57-81.

Bloom, D.E., D. Canning, and B.S. Graham. 2003. Longevity and life-cycle savings. Scandinavian Journal of Economics 105: 319-38. 
Bloom, D.E., D. Canning, and D.T. Jamison. 2004. Health, wealth, and welfare. Finance and Development 31: 10-5.

Caldwell, J.C. 1986. Routes to low mortality in poor countries. Population and Development Review 12: 171-220.

Case, A., D. Lubotsky, and C. Paxson. 2002. Economic status and health in childhood: The origins of the gradient. The American Economic Review 92: 1308-34.

Castro-Leal, F., J. Dayton, L. Demery, and K. Mehra. 2000. Public spending on health care in Africa: Do the poor benefit? Bulletin of the World Health Organization 78: 66-74.

Chen, W. 2010. Health and wealth of nations. Saarbrücken, Germany: Lambert Academic Publishing.

Contoyannis, P., A. Jones, and N. Rice. 2004. The dynamics of health in the British household panel study. Journal of Applied Econometrics 19: 473-503.

Deaton, A. 2002. Policy implications of the gradient of health and wealth. Human Affairs 21: 13-30.

Devlin, N., and P. Hansen. 2001. Health care spending and economic output: Granger causality. Applied Economics Letters 8: 561-4.

Dreger, C., and H.E. Reimers. 2005. Health care expenditures in OECD countries: A panel unit root and cointegration analysis. International Journal of Applied Econometrics and Quantitative Studies 2: 5-20.

Dufour, J.-M., and E. Renault. 1998. Short run and long run causality in time series: Theory. Econometrica 66: 1099-125.

Dufour, J.-M., D. Pelletier, and E. Renault. 2006. Short run and long run causality in time series: Inference. Journal of Econometrics 132: 337-62.

Easterly, W. (1999) Life during growth, Journal of Economic Growth, 4, 239-276.

Erdil, E., and I.H. Yetkiner. 2009. The Granger-causality between healthcare expenditure and output: A panel data approach. Applied Economics. 41: 511-8.

Farahani, M., S.V. Subramanian, and D. Canning. 2009. The effect of changes in health sector resources on infant mortality in the short-run and the long-run: A longitudinal econometric analysis. Social Science \& Medicine 68: 1918-25.

Filmer, D., and L. Pritchett. 1999. The impact of public spending on health: Does money matter. Social Science and Medicine 49: 1309-23.

French, D. 2012. Causation between health and income: A need to panic. Empirical Economics 42: 583-601.

Frijters, P., J.P. Haisken-DeNew, and M.A. Shields. 2005. The causal effect of income on health: Evidence from German reunification. Journal of Health Economics 24: 997-1017.

Granger, C.W.J. 1969. Investigating causal relations by econometric models and crossspectral methods. Econometrica 37: 424-38.

Gregorio, J.D., and J. Lee. 2003. Education and income inequality: New evidence from crosscountry data. Review of Income and Wealth 48: 395-416.

Hansen, C. W. 2012. The relation between wealth and health: Evidence from a world panel of countries. Economics Letters 115: 175-6.

Hanmer, L., R. Lensink, and H. White, H. 2003. Infant and child mortality in developing countries: Analysing the data for robust determinants. Journal of Development Studies 40: 101-18.

Hazan, M. 2012. Life expectancy and schooling: New insights from cross-country data. Journal of Population Economics 25: 1237-48.

Heston, A., R. Summers, and B. Aten. 2011. Penn World Table Version 7.0, Center for International Comparisons of Production, Income and Prices at the University of Pennslyvania.

Hill, K., A.D. Lopez, K. Shibuya, and P. Jha. 2007. Interim measures for meeting needs for health sector data: Births, deaths, and causes of death. The Lancet 370: 1726-35. 
Holtz-Eakin, D., W. Newey, and H.S. Rosen. 1988. Estimating vector autoregressions with panel data. Econometrica 56: 1371-95.

Hsiao, C. 2003. Analysis of panel data. Cambridge, MA: Cambridge University Press.

Hsiao, C., D.C. Mountain, M.W.L Chan, and K.Y. Tsui. 1989. Modeling Ontario regional electricity system demand using a mixed fixed and random coefficients approach. Regional Science and Urban Economics 19: 565-87.

Hsiao, C., M.H. Pesaran, and A.K. Tahmiscioglu. 1999. Bayes estimation of short-run coefficients in dynamic panel data models. In Analysis of Panels and Limited Dependent Variables Models, eds., C. Hsiao, L.F. Lee, K. Lahiri, M.H. Pesaran, 268-96. Cambridge, MA: Cambridge University Press.

Hurlin, C. 2005. Granger causality tests in panel data models with fixed coefficients. Revue Economique 56: 1-11.

Hurlin, C. 2008. Testing for Granger non-causality in heterogeneous panels, Working Paper, Laboratoire d'Economie D'Orleans, University of Orleans.

Hurlin, C., and B. Venet. 2003. Granger causality tests in panel data models with fixed coefficients. Mimeograph, Universitie Paris I.

Hurlin, C. and B. Venet. 2008. Financial development and growth: A re-examination using a panel Granger causality test, Working Paper, Laboratoire d'Economie D'Orleans, University of Orleans.

Juselius, K., and Z. Mladenovic. 2002. High inflation, hyperinflation and explosive roots. The case of Yugoslavia, Working Paper, University of Copenhagen and University of Belgrade.

Kiviet, J.F. 1995. On bias, inconsistency, and efficiency of various estimators in dynamic panel data models. Journal of Econometrics 68: 53-78.

Larson, J.S. 1991. Two scales for measuring international health status. Evaluation \& the Health Professions 14: 422-37.

Michaud, P.-C., and A. van Soest. 2008. Health and wealth of elderly couples: Causality tests using dynamic panel data models. Journal of Health Economics 27: 1312-25.

Murray, C.J.L., J.A. Salomon, and C. Mathers. 2000, A critical examination of summary measures of population health. Bulletin of the World Health Organization 78: 981-94.

Musgrove, P. 1996. Public and private roles in health, World Bank Discussion Paper \#339.

Mushkin, S.J. 1962. Health as an investment. Journal of Political Economy 70: S129-57.

Nair-Reichert, U., and D. Weinhold. 2001. Causality tests for cross-country panels: A new look at FDI and economic growth in developing countries. Oxford Bulletin of Economics and Statistics 63: 153-71.

Pesaran, M.H., and R.P. Smith. 1995. Estimating long run relationships from dynamic heterogenous panels. Journal of Econometrics 68: 79-113.

Pesaran, M.H., Y. Shin, and R.P. Smith. 1999. Pooled mean group estimation of dynamic heterogenous panels. Journal of the American Statistical Association 94: 621-34.

Pritchett, L., and L.H. Summers. 1996. Wealthier is healthier. Journal of Human Resources 31: 841-68.

Qureshi, H. 2008. Explosive roots in level vector autoregressive models, Working Paper \#0802R, Department of Economics, Ohio State University.

Rodgers, G.B. 1979. Income and inequality as determinants of mortality: An international cross-section analysis. Population Studies 33: 343-51.

Ruger, P., D. Jamison, D. Bloom, and D. Canning. 2001. Health and the economy. In International Public Health: Diseases, Programs, Systems and Policies, eds., M. Merson, B. Black, A. Mills, 601-47. Cambridge, MA: Jones and Bartlett Publishers.

Sen, A. 1987. The standard of living: the Tanner lectures. Cambridge University Press; Cambridge. 
Sims, C. 1989. Modeling Trends. Paper presented at the August 1989 American Statistical Association Meetings.

Smith, J.P. 1999. Healthy bodies and thick wallets: The dual relation between health and economic status. Journal of Economic Perspectives 13: 145-66.

Strauss, J., and D. Thomas. 1998. Health, nutrition, and economic development. Journal of Economic Literature 36: 766-817.

Subbarao, K., and L. Raney. 1995. Social gains from female education: A cross-national study. Economic Development and Cultural Change 44: 105-28.

Sullivan, D.F. 1966. Conceptual problems in developing an index of health, United States Public Health Services Publication Series 1000, Vital and Health Statistics Series 2, No. 17. Washington DC, National Center for Health Statistics.

Sullivan, D.F. 1971. A single index of mortality and morbidity. HSMHA Health Reports 86: 347-54.

Swamy, P.A.V.B. 1970. Efficient inference in a random coefficient regression model. Econometrica 38: 311-23.

Thomas, D., J. Strauss, and M. Henriques. 1990. Child survival, height for age and household characteristics in Brazil. Journal of Development Economics 33: 197-234.

Weinhold, D. 1999. A dynamic "fixed effects" model for heterogenous panel data, Working Paper, London School of Economics.

Zakir, M. and P. Wunnava, 1999. Factors affecting infant mortality rates: Evidence from cross-sectional data. Applied Economics Letters 6: 271-3.

Zhang, J., J. Zhang, and R. Lee. 2003. Rising longevity, education, savings, and growth. Journal of Development Economics 70: 83-101. 


\section{Appendix A. Core estimation tables}

Table A.1: Coefficient estimates (standard errors) from Method I

\begin{tabular}{|c|c|c|c|c|c|}
\hline $\begin{array}{c}\text { Coefficient } \\
\text { on GDP }\end{array}$ & $\begin{array}{c}\text { Health } \\
\text { equation } \\
(a=1)\end{array}$ & $\begin{array}{c}\text { Wealth } \\
\text { equation } \\
(a=2)\end{array}$ & $\begin{array}{c}\text { Coefficient } \\
\text { on IMR }\end{array}$ & $\begin{array}{c}\text { Health } \\
\text { equation }\end{array}$ & $\begin{array}{c}\text { Wealth } \\
\text { equation }\end{array}$ \\
\hline$\pi_{a 2,11}$ & $-0.085(0.299)$ & $1.435(0.833)$ & $\pi_{11,1}$ & $1.535(0.071)$ & n.a. \\
\hline$\pi_{a 2,21}$ & $0.052(0.296)$ & $-0.410(0.810)$ & $\pi_{11,2}$ & $-0.533(0.073)$ & n.a. \\
\hline$\pi_{a 2,12}$ & $-0.091(0.236)$ & $-1.632(2.754)$ & $\pi_{21,11}$ & n.a. & $-0.454(0.679)$ \\
\hline$\pi_{a 2,22}$ & $0.050(0.243)$ & $2.530(2.721)$ & $\pi_{21,21}$ & n.a. & $0.453(0.669)$ \\
\hline$\pi_{a 2,13}$ & $-0.038(0.098)$ & $1.253(0.327)$ & $\pi_{21,12}$ & n.a. & $-3.655(3.325)$ \\
\hline$\pi_{a 2,23}$ & $0.003(0.097)$ & $-0.290(0.308)$ & $\pi_{21,22}$ & n.a. & $3.483(3.369)$ \\
\hline$\pi_{a 2,14}$ & $-0.255(0.151)$ & $1.375(0.281)$ & $\pi_{21,13}$ & n.a. & $-0.333(0.329)$ \\
\hline$\pi_{a 2,24}$ & $0.216(0.147)$ & $-0.447(0.262)$ & $\pi_{21,23}$ & n.a. & $0.373(0.345)$ \\
\hline$\pi_{a 2,15}$ & $0.043(0.110)$ & $0.815(0.256)$ & $\pi_{21,14}$ & n.a. & $-0.115(0.407)$ \\
\hline$\pi_{a 2,25}$ & $-0.069(0.108)$ & $0.119(0.235)$ & $\pi_{21,24}$ & n.a. & $-0.044(0.421)$ \\
\hline$\pi_{a 2,16}$ & $0.089(0.113)$ & $0.836(0.232)$ & $\pi_{21,15}$ & n.a. & $-0.902(0.317)$ \\
\hline$\pi_{a 2,26}$ & $-0.104(0.119)$ & $0.172(0.225)$ & $\pi_{21,25}$ & n.a. & $0.778(0.332)$ \\
\hline$\pi_{a 2,17}$ & $-0.254(0.166)$ & $1.625(0.476)$ & $\pi_{21,16}$ & n.a. & $0.105(0.221)$ \\
\hline$\pi_{a 2,27}$ & $0.253(0.170)$ & $-0.523(0.479)$ & $\pi_{21,26}$ & n.a. & $-0.164(0.211)$ \\
\hline & & & $\pi_{21,17}$ & n.a. & $-0.299(0.290)$ \\
\hline & & & $\pi_{21,27}$ & n.a. & $0.457(0.294)$ \\
\hline
\end{tabular}

Notes: Figures are coefficient estimates (standard errors) for equation (2) imposing outcomes of time stationarity tests. Period effects are not reported. "n.a." denotes not applicable. 
Table A.2: Summary coefficient estimates (standard errors) for fixed coefficients (Method II)

\begin{tabular}{|c|c|c|c|c|c|}
\hline Coefficient & Range for 58 countries & Argentina & Ethiopia & India & Malaysia \\
\hline$\gamma_{11, i 1}$ & $\underset{(0.167)}{-0.114}, \underset{(0.256)}{1.391} ; 0.725$ & $\begin{array}{l}0.859 \\
(0.052)\end{array}$ & $\begin{array}{l}0.786 \\
(0.215)\end{array}$ & $-\underset{(0.167)}{-0.114}$ & $\begin{array}{l}1.044 \\
(0.170)\end{array}$ \\
\hline$\gamma_{12, i 1}$ & $\underset{(0.376)}{-1.625} \underset{(0.135)}{0.550 ;}-0.054$ & $\begin{array}{l}-0.321 \\
(0.136)\end{array}$ & $\begin{array}{l}0.299 \\
(0.448)\end{array}$ & $\begin{array}{l}-0.768 \\
(0.138)\end{array}$ & $\begin{array}{l}0.140 \\
(0.167)\end{array}$ \\
\hline$\gamma_{21, i 1}$ & $\underset{(0.480)}{-1.702, \underset{(1.054)}{1.167 ;}-0.235}$ & $\begin{array}{l}-0.196 \\
(0.103)\end{array}$ & $\begin{array}{l}-0.252 \\
(0.243)\end{array}$ & $\begin{array}{l}-0.062 \\
(0.714)\end{array}$ & $\begin{array}{l}-0.043 \\
(0.600)\end{array}$ \\
\hline$\gamma_{22, i 1}$ & $\underset{(0.982)}{-0.713}, \underset{(0.626)}{-0.177 ; 0.374}$ & $\begin{array}{l}0.194 \\
(0.249)\end{array}$ & $\begin{array}{c}-0.182 \\
(0.299)\end{array}$ & $\begin{array}{l}1.177 \\
(0.626)\end{array}$ & $\begin{array}{l}0.939 \\
(0.589)\end{array}$ \\
\hline
\end{tabular}

Notes: Figures are coefficient estimates (PCSEs in parentheses) for equation (3) when estimated by LS. In the "Range" column, the figures presented are the "smallest, largest; mean" estimates with their corresponding PCSEs in parentheses. Period and country effects are not reported. 